\title{
Dynamic Nonlinear and Residual Deformation Behaviors of the Fly Ash-Modified Loess
}

\author{
Qian Wang $\left(\mathbb{D},{ }^{1}\right.$ Jun Wang, ${ }^{1}$ Xiumei Zhong $\mathbb{D}^{1},{ }^{1}$ Haiping $\mathrm{Ma}^{2}{ }^{2}$ and Xiaowei $\mathrm{Xu}{ }^{1}$ \\ ${ }^{1}$ Key Laboratory of Loess Earthquake Engineering, China Earthquake Agency \& Gansu Province, Lanzhou 730000, China \\ ${ }^{2}$ Gansu Earthquake Agency, Lanzhou 730000, China \\ Correspondence should be addressed to Qian Wang; wangq0930@126.com and Xiumei Zhong; xmzhong26@163.com
}

Received 8 July 2021; Revised 30 October 2021; Accepted 12 November 2021; Published 6 December 2021

Academic Editor: Rui Moreira

Copyright (c) 2021 Qian Wang et al. This is an open access article distributed under the Creative Commons Attribution License, which permits unrestricted use, distribution, and reproduction in any medium, provided the original work is properly cited.

Metastable loess soils can deform, inducing geological and engineering disasters. Therefore, the behavior of the loess under dynamic load is gaining massive attention from researchers to improve the strength of the soils. Fly ash mixed with loess can improve strength and reduce construction costs and environmental pollution. Moreover, it has strong economic and social benefits. This paper investigates the influence of fly ash on the dynamic properties of the modified loess through a series of dynamic triaxial tests of the fly ash modified loess with different fly ash contents. The treated soil samples were prepared using a static compaction method in both ends and cured for 28 days. The dynamic shear modulus ratio, the damping ratio, and the dynamic residual strain of the modified loess were analyzed. The variation characteristics of the dynamic shear modulus ratio and damping ratio with the dynamic shear strain of the fly ash modified loess were obtained. The effect of fly ash content on the dynamic nonlinear parameters of the modified loess was also investigated. In addition, the relationship between the dynamic residual strain and the fly ash content was discussed. The results show that the dynamic shear modulus ratio of fly ash modified loess decreases nonlinearly with the increase in the dynamic shear strain. However, the attenuation rate difference of the curves is small. The damping ratio increases gradually with increasing dynamic shear strain. Under a certain dynamic shear strain level, the damping ratio decreases with the increase in the fly ash content. The dynamic residual strain increases with the increase in the dynamic stress. However, it decreases with the increase in the fly ash content. When the fly ash content is between $10 \%$ and $20 \%$, the dynamic residual strain of fly ash modified loess is reduced rapidly. However, when the fly ash content exceeds $20 \%$, the dynamic residual strain decreases slowly. The fly ash content of $20 \%$ could be suggested as an optimal content for seismic resistance of the loess foundation.

\section{Introduction}

Loess is a kind of unique soil, which is widely distributed in northern China. Natural loess is transported and deposited by wind force [1]. Under the action of the exogenetic force, a typical overhead pore structure is formed with the soil's vertical joints and crack distribution. At the same time, due to the point-contact characteristics of loess particles and the solubility of cementing substances between particles, the strength of the soil skeleton is weak [2].

Loess is mainly located between Tibetan Plateau and Inner Mongolia Plateau in China. Due to the influence of the northeast pushing of the Tibetan Plateau, the geological structure is complex in this area. Furthermore, neotectonic movement is very strong, and strong earthquakes frequently occur $[3,4]$. In addition, the Loess Plateau is the main battlefield in the Strategy of Developing Western of China, as well as one of the core regions of the Belt and Road Initiative of the world. Many high-grade highways, high-speed railways, and urban rail transit are under construction. Under this background, loess with metastable structure is easy out of shape under the action of dynamic loads such as strong earthquakes, which induces a considerable number of geological disasters and engineering diseases [5-11]. Thus, behaviors in the loess area under dynamic load have attracted extensive attention by researchers [12-15].

As a solid waste discharged from coal-fired power plants, the annual output of fly ash is large in the world. Its 
accumulation and storage occupy a large amount of land. Besides, the dust caused by the fly ash with small particles and lightweight had polluted the environment significantly. Current literature shows that fly ash has porosity, high surface area, and good absorbability, and it has hydrolysis reaction characteristics similar to cement [16-18]. Therefore, the development and utilization of fly ash in many aspects can not only save the land and protect the environment but also realize the reuse of waste resources, which has good social, economic, and ecological benefits.

The ecological environment in the loess region is very fragile, and the deterioration effect of many projects is increasing in terms of the ecological environment. As an improved material with good qualities, fly ash applications are becoming more popular for engineering construction in loess areas [19-25]. The research shows that the addition of fly ash into loess can not only increase the strength of improved soil but also significantly reduce the compressibility and collapsibility of loess [26, 27], which has a significant effect on improving the engineering properties of loess. However, the existing research on the mechanical properties of fly ash modified loess is mostly focused on the statics behaviors of the mixture. Only a few results are related to the dynamic characteristics of the fly ash modified loess, which focus on dynamic elastic modulus, damping ratio, seismic subsidence, and liquefaction behaviors, respectively [28-32]. The characteristics of fly ash improved loess of dynamic nonlinear and residual strain are still not paid enough attention.

In this paper, the characteristics of the dynamic nonlinear and dynamic residual strain of the fly ash modified loess are investigated, and the influence of regulating fly ash content on the initial dynamic shear modulus ratio, damping ratio, and the dynamic residual strain of loess is discussed. This study contributes to the current literature as follows:

(1) The results show that the maximum dynamic shear modulus ratio of loess will increase, and the damping ratio and dynamic residual strain of loess will reduce with mixing an appropriate amount of fly ash into loess.

(2) The research result can provide references for seismic design and seismic risk analysis of major projects in loess areas, have certain reference value for the use of the fly ash modified loess as the subgrade engineering materials, and have important scientific significance for localization of engineering construction materials and ecological civilization construction in loess areas.

In Section 2, the equipment, tests, and methods are introduced. Then, the results are detailed in Section 3. Section 4 discusses the results, followed by the conclusion in Section 5 .

\section{Sample, Test Equipment, and Methods}

The loess used in the test was taken from a site at the Beiyuan tableland in Linxia County, Gansu Province, as shown in Figure 1. The loess belongs to the Malan loess formed in the
Late Pleistocene. Considering the shallow loess is generally used as the filler in the project, the soil sampling depth is 4.0-4.2 $\mathrm{m}$. The particle size distribution (PSD) curve of the loess is shown in Figure 2, and the grain size distribution parameters including D10, D30, D60, Cu, and Cc are shown in Table 1. The physical indexes of loess, including the initial unit weight, moisture content, specific gravity, liquid limit, plastic limit, and Passion ratio, are taken from the laboratory, as shown in Table 2 [33-39].

The fly ash used in the test was taken from the thermo plant in Lanzhou City. It is a kind of dry and powdered solid with a grey colour, as shown in Figure 3(a). The SEM image of the fly ash is shown in Figure 3(b). The PSD curve of the fly ash is shown in Figure 4, and the grain size distribution parameters including D10, D30, D60, Cu, and Cc are shown in Table 1. The chemical components are shown in Table 3. The LOI (loss on ignition) of the fly ash is 4.93 .

The specimens and the sample preparation instrument are shown in Figure 5. The loess samples taken from the site were crushed by a rubber hammer and sieved by a sieve with a hole diameter of $2 \mathrm{~mm}$.

The temperature of the oven was set at $110^{\circ} \mathrm{C}$, and the sifted loess was dried for $12 \mathrm{~h}$ to obtain the soil used in the test. The fly ash used in the test was also dried in the oven at $110^{\circ} \mathrm{C}$ for $12 \mathrm{~h}$. Based on the principle of mass ratio, first, the soil material and fly ash were dry-mixed evenly, and then water was to fully mix the fly ash modified loess. The mass ratio of fly ash in each group of soil material is $0,5 \%, 10 \%$, $15 \%, 20 \%$, and $25 \%$. In order to ensure the comparability of test results, the moisture content of each group of samples adopted the optimal moisture content of plain loess. Put the mixed fly ash modified loess with different proportions in the sealed bag for 24 hours to ensure a good distribution of soil moisture content. The fly ash modified loess samples were prepared by the two-end static pressure method. The diameter and height of each group of samples are $50 \mathrm{~mm}$ and $100 \mathrm{~mm}$, respectively. After the samples were prepared, standard curing was carried out under constant temperature and humidity, and the curing age was 28 days. Before the test, the average dry density of fly ash modified loess ranged from $1.43 \mathrm{~g} / \mathrm{cm}^{3}$ to $1.44 \mathrm{~g} / \mathrm{cm}^{3}$, and the average moisture content ranged from $15.91 \%$ to $16.14 \%$.

The test equipment used in the study for dynamic triaxial tests was the DSD-160 electromagnetism dynamic triaxial instrument. During the test, the samples took anisotropic consolidation firstly. In order to ensure the comparability of the test results of different groups of samples, the consolidation ratio was set as 1.695 uniformly. The axial deformation was measured during the consolidation process and took the axial deformation of $5 \mathrm{~min}$, which was less than $0.005 \%$, as the standard of the sample consolidation stability. The equivalent sine wave with a frequency of $1 \mathrm{~Hz}$ was used as the dynamic load to conduct cyclic shear on the samples after consolidation, and there was no drainage during the test. For the dynamic shear modulus-damping ratio test, the same sample was used. After the sample consolidation was stabilized, the dynamic stress was increased by $8 \mathrm{KPa}$ at the first three levels and then increased by $5 \mathrm{KPa}$ at the last nine levels, with the consolidation pressure kept unchanged, and 


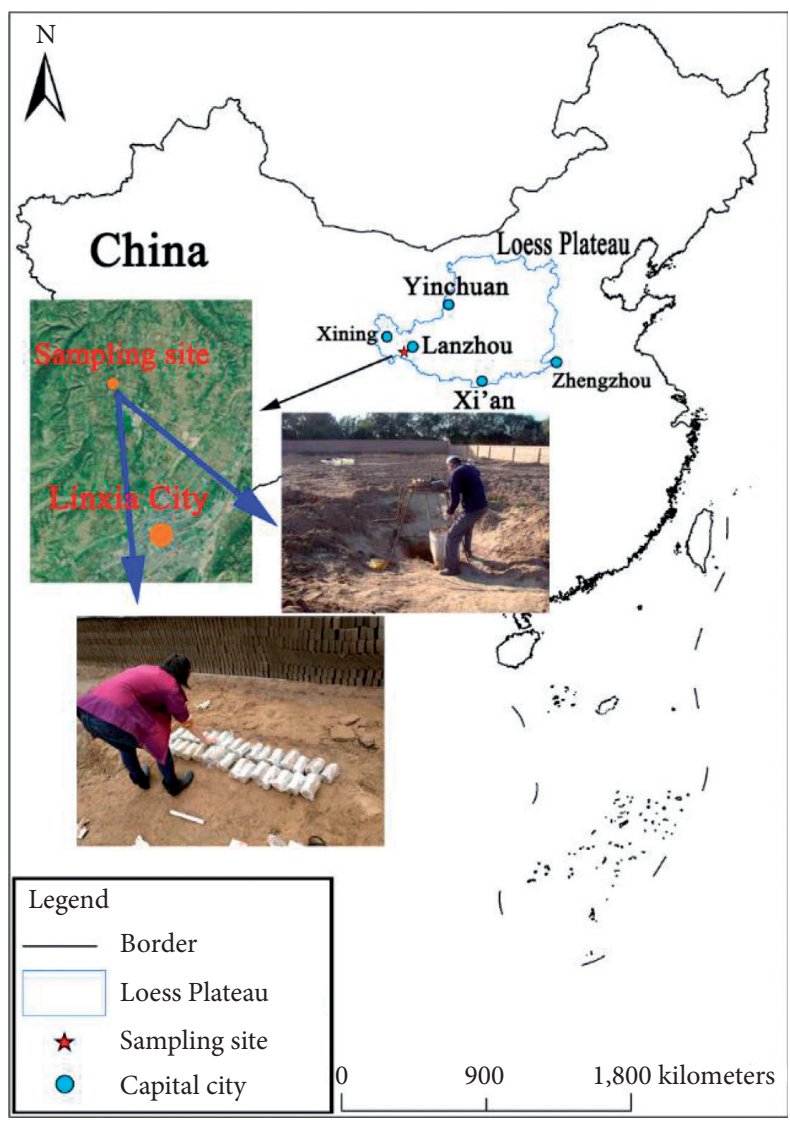

FIGURE 1: Location of the sampling site.

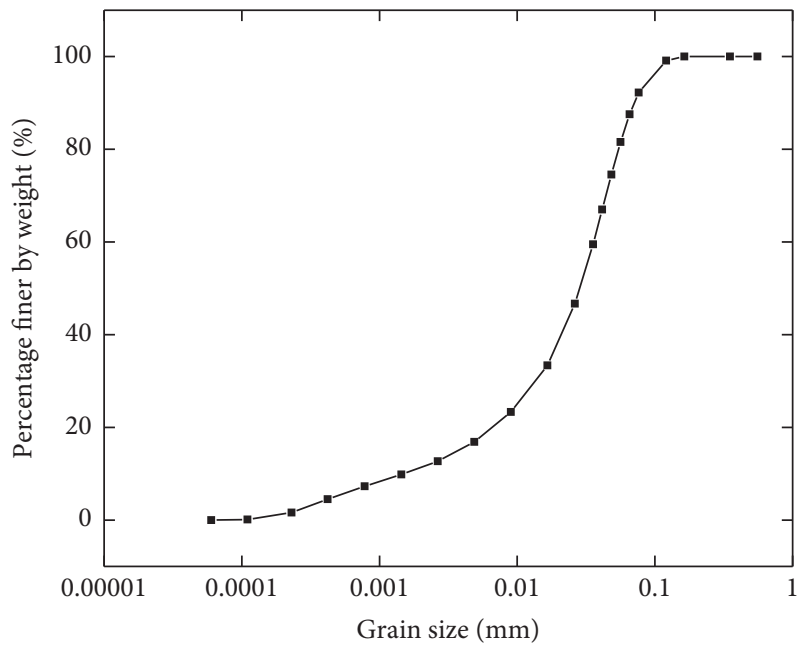

Figure 2: Particle size distribution of the loess used in this study.

each level of dynamic stress loaded ten times until the sample had a large axial deformation. For the dynamic residual deformation test, under the same consolidation state, the dynamic stress of different amplitudes was applied to three samples with similar physical parameters in each group until large residual deformation occurred. The maximum loading vibration time of each sample was 40 [40-44]. The consolidation and loading conditions of each group of samples are shown in Table 4 .

\section{Results and Analysis}

3.1. Dynamic Shear Modulus Ratio and Damping Ratio of the Fly Ash Modified Loess. The dynamic shear modulus ratio $G \mathrm{~d} / G \mathrm{dmax}$ and dynamic shear strain $\gamma \mathrm{d}$ of fly ash modified loess were calculated according to the results of the dynamic triaxial test [45], and the curve of dynamic shear modulus ratio-dynamic shear strain was drawn as shown in Figure 6. It can be seen from Figure 6 that the dynamic shear modulus ratio of different proportions of fly ash modified loess decreases nonlinearly with the increase in dynamic shear strain, and the shape of each curve is relatively similar. When the dynamic shear strain is less than $0.01 \%$, the dynamic shear modulus ratio decreases slowly with the increase in dynamic shear strain. The dynamic shear modulus ratio of fly ash modified loess is close to that of the compacted loess. When the dynamic shear strain is more than $0.01 \%$, the dynamic shear modulus ratio decreases rapidly with the increase in dynamic shear strain. The attenuation rate of the curve of dynamic shear modulus ratio-dynamic shear strain of fly ash modified loess is slower than that of the compacted loess. When the fly ash content is less than $15 \%$, the dynamic shear modulus ratio of fly ash modified loess is closed to that of the compacted loess. The dynamic shear modulus ratio of fly ash modified loess increases slightly with the continuous increase in the fly ash content, which indicates that the dynamic stiffness of fly ash modified loess has a certain degree of improvement after the fly ash content exceeds $15 \%$. 
TABle 1: Grain size distribution parameters.

\begin{tabular}{lcc}
\hline Grain size distribution parameters & Loess & Fly ash \\
\hline D10 $(\mathrm{mm})$ & 0.0015 & 0.0013 \\
D30 $(\mathrm{mm})$ & 0.0143 & 0.0054 \\
D60 $(\mathrm{mm})$ & 0.0356 & 0.0124 \\
Cu & 23.73 & 9.54 \\
Cc & 3.83 & 1.81 \\
\hline
\end{tabular}

Table 2: Physical indexes of loess specimens.

\begin{tabular}{lc}
\hline Soil property & Value \\
\hline Initial unit weight $\left(\mathrm{kN} / \mathrm{m}^{3}\right)$ & 13.30 \\
Moisture content $(\%)$ & 5.43 \\
Specific gravity & 2.70 \\
Liquid limit $(\%)$ & 25.60 \\
Plastic limit (\%) & 16.40 \\
Plasticity index & 9.20 \\
Poisson ratio & 0.31 \\
\hline
\end{tabular}

The damping ratio $D$ of the fly ash modified loess was calculated by the hysteretic curve method, and the curve of damping ratio-dynamic shear strain was drawn as shown in Figure 7. It can be seen from Figure 7 that the damping ratio of fly ash modified loess with different proportions presents a nonlinear increase with the increase in the dynamic shear strain. When the dynamic shear strain is less than $0.005 \%$, the damping ratio of each group of fly ash modified loess increases slowly. When the dynamic shear strain is more than $0.005 \%$, the damping ratio increases rapidly with the increase in the dynamic shear strain. When the dynamic shear strain is more than $0.2 \%$, the growth rate of the damping ratio tends to slow down. The damping ratio of fly ash modified loess shows an obvious difference with the different fly ash contents under the same dynamic shear strain. When the fly ash content is less than $10 \%$, the damping ratio of fly ash modified loess is close to that of the compacted loess. When the fly ash content is more than $10 \%$, the damping ratio of fly ash loess decreases obviously with the increase in the fly ash content. When the dynamic shear strain is less than $0.2 \%$, the damping ratio of fly ash modified loess with the content of $20 \%$ is the lowest. When the dynamic shear strain exceeds $0.2 \%$, the damping ratio of fly ash modified loess with the content of $25 \%$ is the minimum.

In order to further analyze the influence of fly ash content on the dynamic nonlinearity of fly ash modified loess, the relation curves of the maximum dynamic shear modulus, maximum damping ratio, and fly ash content of fly ash modified loess were drawn according to the test and calculation results, as shown in Figure 8. It can be seen from Figure 8 that, with the increase in fly ash content, the maximum dynamic shear modulus of fly ash modified loess increases nonlinearly, and its growth tendency presents the characteristics of slow growth, rapid growth, and slow growth. The relationship between the maximum dynamic shear modulus of fly ash modified loess and the yield of fly ash can be fitted by formula (1), in which a1, a2, and a3 are the fitting parameters. With the increase in fly ash content, the maximum damping ratio first increases slowly and then decreases sharply. The relationship between the maximum damping ratio and the yield of fly ash follows a quadratic function, as shown in formula (2), in which b1, b2, and b3 are fitting parameters. When the fly ash content $m \leq 10 \%$, the maximum dynamic shear modulus and the maximum damping ratio of the fly ash modified loess change a little. When the fly ash content was $15 \%, 20 \%$, and $25 \%$, the maximum dynamic shear modulus of fly ash modified loess, compared with that of the compacted loess, increased by $13.58 \%, 24.99 \%$, and $30.65 \%$, respectively, and the maximum damping ratio of fly ash modified loess, compared with that of the compacted loess, decreases by $4.73 \%, 12.75 \%$, and $21.01 \%$, respectively. It can be seen that the dynamic stiffness of the fly ash modified loess increases significantly compared with compacted loess:

$$
\begin{gathered}
G_{d \max }=a_{1}+\frac{a_{2}}{1+10^{\log a_{3} m},} \\
D_{\text {max }}=b_{1}+b_{2} m+b_{3} m^{2} .
\end{gathered}
$$

\subsection{Dynamic Residual Deformation of the Fly Ash Modified} Loess. Figure 9 shows the variation curves of dynamic residual strain $\varepsilon p$ of fly ash modified loess with different fly ash contents under the conditions of different dynamic stress. It can be seen from Figure 9 that the dynamic residual strain of fly ash modified loess decreases with the increase in fly ash content under the conditions of different dynamic stress. When the fly ash content $m \leq 10 \%$, the dynamic residual strain changes a little with the increase in fly ash content, but it will increase significantly with the increase in dynamic stress. When the fly ash content reaches $15 \%, 20 \%$, and $25 \%$, the dynamic residual strain of fly ash modified loess decreases by 0.50 times, 0.80 times, and 0.79 times, respectively, under the conditions of dynamic stress of $50 \mathrm{KPa}$ and vibration times of 10 , the dynamic residual strain of fly ash modified loess decreases by 0.85 times, 1.40 times, and 1.39 times, respectively, under the conditions of dynamic stress of $50 \mathrm{KPa}$ and vibration times of 40; the dynamic residual strain of fly ash modified loess decreases by 1.60 times, 2.85 times, and 2.95 times, respectively, under the conditions of dynamic stress of $100 \mathrm{KPa}$ and vibration times of 1 ; the dynamic residual strain of fly ash modified loess decreases by 1.70 times, 3.58 times, and 3.62 times, respectively, under the conditions of dynamic stress of $100 \mathrm{KPa}$ and vibration times of 40; the dynamic residual strain of fly ash modified loess decreases by 2.50 times, 5.48 times, and 5.65 times, respectively, under the conditions of dynamic stress of $150 \mathrm{KPa}$ and vibration times of 10; and the dynamic residual strain of fly ash modified loess decreases by 2.57 times, 5.90 times, and 6.37 times, respectively, under the conditions of dynamic stress of $150 \mathrm{KPa}$ and vibration times of 40 .

When the fly ash content reaches $20 \%$, the dynamic residual strain of fly ash modified loess only decreases slowly with the increase in fly ash content. Besides, for fly ash modified loess with $m \leq 15 \%$ and compacted loess, the dynamic stress has a significant influence on the dynamic residual deformation; that is, the dynamic residual 


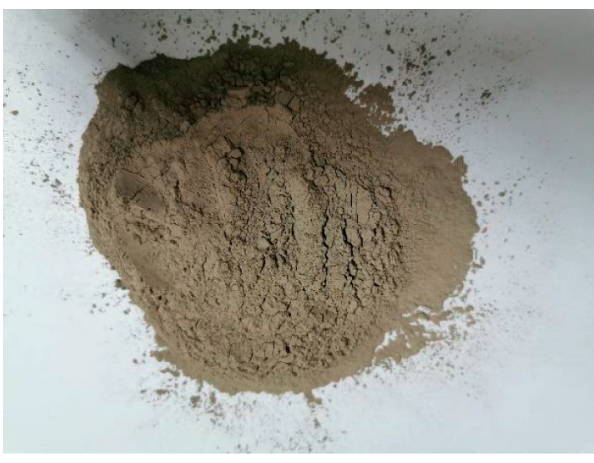

(a)

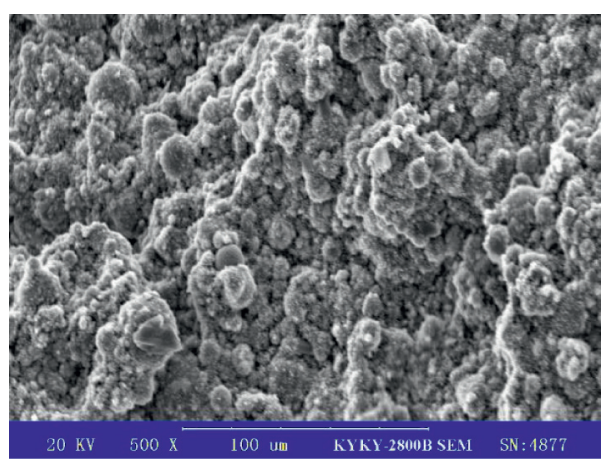

(b)

FIgure 3: The fly ash used in this study, (a) the fly ash power, and (b) the SEM image.

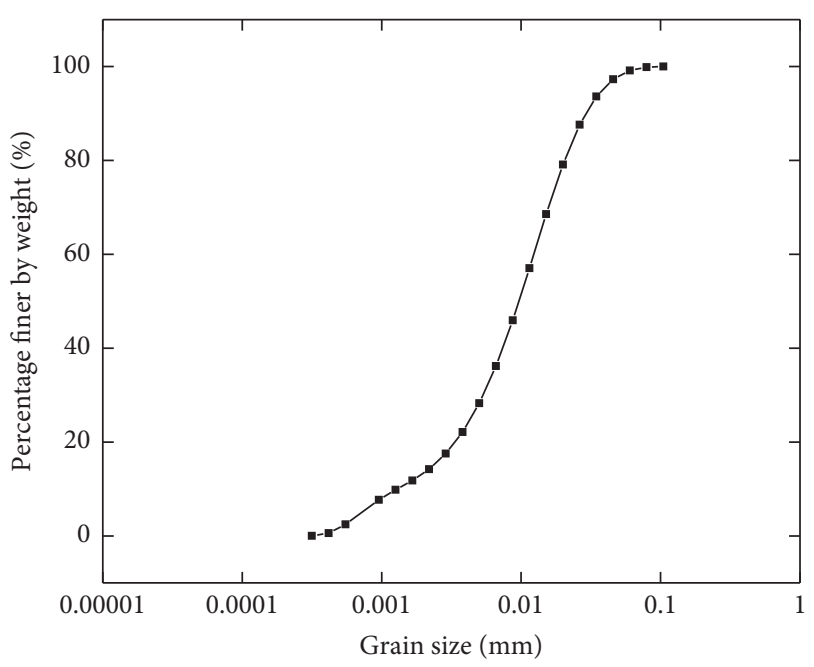

FIGURE 4: Particle size distribution of the fly ash used in this study.

TABle 3: Major chemical constituent of fly ash.

\begin{tabular}{lc}
\hline Chemical composition & Value \\
\hline $\mathrm{SiO}_{2}$ & 52.04 \\
$\mathrm{Al}_{2} \mathrm{O}_{3}$ & 20.22 \\
$\mathrm{Fe}_{2} \mathrm{O}_{3}$ & 4.19 \\
$\mathrm{MgO}$ & 12.57 \\
$\mathrm{CaO}$ & 5.47 \\
$\mathrm{SO}_{3}$ & 0.45 \\
\hline
\end{tabular}

deformation increases significantly with the increase in the dynamic stress. When the fly ash content reaches $20 \%$, the dynamic residual strain of fly ash modified loess increases slightly with the increase in dynamic stress, which indicates that the antideformation ability of soil is significantly enhanced [31].

\section{Discussion}

Considering Figures 6-9, mixing fly ash into the loess could significantly influence the dynamic shear modulus ratio, damping ratio, and dynamic residual strain of the soil, which mainly shows that the dynamic shear modulus ratio will increase with the increase in fly ash content. In contrast, the damping ratio and dynamic residual strain will decrease with the increase in fly ash content. The dynamic stiffness and antidynamic deformation ability of foundation soil can be effectively improved by adding fly ash into the loess. Therefore, the dynamic stiffness and antideformation ability of foundation soil can be effectively improved by mixing fly ash into the loess. According to Figures 6 to 9, when the fly ash content is small $(5 \%, 10 \%)$, the dynamic shear modulus ratio, damping ratio, and dynamic residual strain of fly ash modified loess are close to those of compacted loess, which indicates that the dynamic characteristics of fly ash modified loess are less affected when the fly ash content is small, and the improvement effect of fly ash on the soil is not obvious. When the fly ash content reaches $15 \%$, the improvement effect of fly ash on loess tends to be obvious, which showed that the maximum dynamic shear modulus of fly ash modified loess increases obviously, and the damping ratio and dynamic residual strain decreases obviously. When the fly ash content reaches $20 \%$, the improvement effect of fly ash is more obvious, which is shown as the attenuation of dynamic shear modulus ratio-damping ratio curve of fly ash modified loess decreases; the maximum dynamic shear modulus ratio increases significantly, and the damping ratio and dynamic residual strain decrease significantly. Compared with the fly ash modified loess with fly ash content of $20 \%$, the maximum dynamic shear modulus of the fly ash modified loess with fly ash content of $25 \%$ increases, and the maximum damping ratio of that decreases significantly. However, at the same dynamic shear strain level, the dynamic shear modulus is similar, the damping ratio curves intersect, and the dynamic residual strain changes a little at the same dynamic shear strain level. Considering the seismic behavior and treatment cost of the foundation, when the fly ash content is $20 \%$, it can not only improve the dynamic stiffness characteristics of soil but also effectively enhance the antiresidual deformation ability of the soil. Therefore, fly ash content of $20 \%$ can be used as the recommended value for the seismic treatment of fly ash modified loess foundation, which is consistent with the results of [29, 30, 46]. Through the above analysis, it can be seen that fly ash content has a significant influence on the dynamic nonlinear parameters and dynamic residual strain of fly ash modified loess. With the increase in fly ash content, the dynamic nonlinear parameters and dynamic residual strain of fly ash modified loess both have 


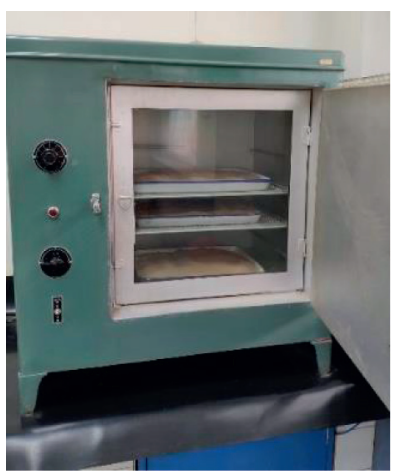

(a)

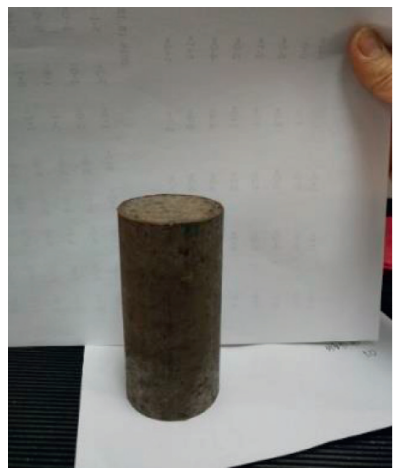

(d)

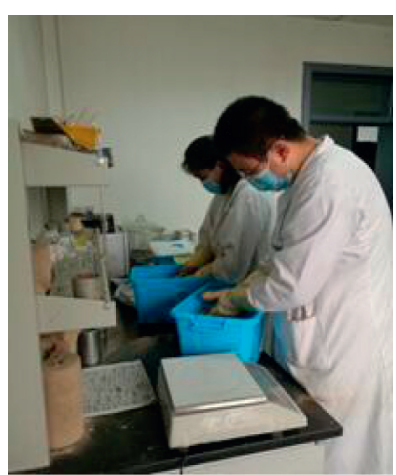

(b)

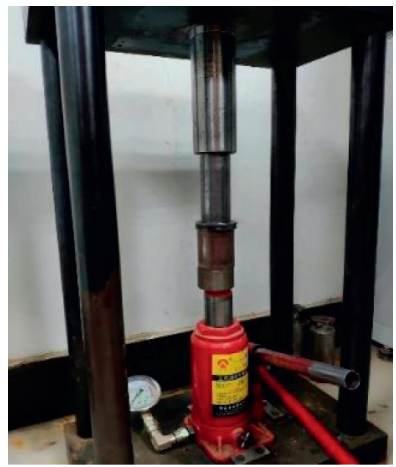

(e)

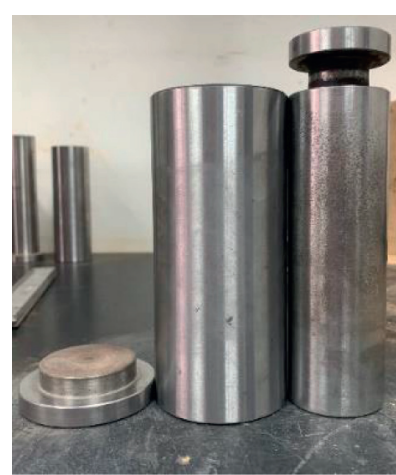

(c)

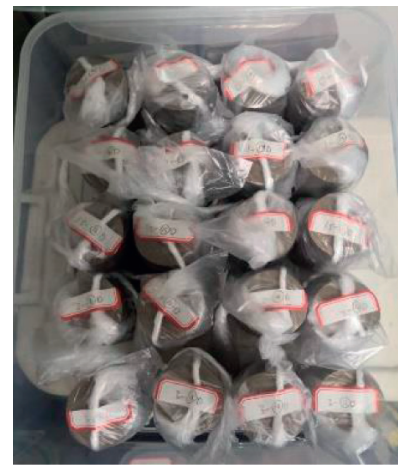

(f)

Figure 5: Process and instruments for the fly ash modified sample preparation: (a) dried, (b) mix and stir, (c) mold for sample preparing, (d) equipment for sample preparing, (e) specimen, and (f) curing process.

TABLE 4: Loading conditions $[31,38,39]$.

\begin{tabular}{lccccc}
\hline $\begin{array}{l}\text { Specimen } \\
\text { groups }\end{array}$ & Tests & $\begin{array}{c}\text { Effective confining } \\
\text { pressure }(\mathrm{KPa})\end{array}$ & $\begin{array}{c}\text { Consolidation } \\
\text { Coefficient }\end{array}$ & $\begin{array}{c}\text { Dynamic stress (KPa) } \\
\text { frequency (Hz) }\end{array}$ & $\begin{array}{c}\text { Loading of } \\
\text { cycles }\end{array}$ \\
\hline $\begin{array}{l}m=0 \\
m=5 \%\end{array}$ & $\begin{array}{c}\text { Dynamic modulus and } \\
\text { damping ratio }\end{array}$ & 59 & & $14,22,30,35,40,45,50$, & 10 \\
$m=10 \%$ & Seismic subsidence & 118 & 1.695 & $5,60,65,70,75$ & 1 \\
$m=15 \%$ & & & & $50,100,150$ \\
$m=20 \%$ & & & & 40 \\
$m=25 \%$ & & & & \\
\hline
\end{tabular}

some change. However, there are differences in the improvement effect of fly ash content on the dynamic properties of fly ash modified loess. The dynamic parameters of fly ash modified loess with fly ash content of $10 \%$ are close to those of compacted loess. According to Figures 6-9, when $20 \%$ of fly ash is added into the loess, the dynamic stiffness of fly ash modified loess is significantly increased, and the dynamic residual deformation is significantly reduced, which indicates that the fly ash has a significant improvement effect on soil. To further explain the internal mechanism of the influence of fly ash content on dynamic shear modulus, damping ratio, and dynamic residual strain of fly ash modified loess, the mesostructure of fly ash modified loess with different contents was tested by SEM. Figure 6 shows the SEM test results of compacted loess and fly ash modified loess, in which the fly ash modified loess has a fly ash content of $10 \%, 15 \%$, and $20 \%$, respectively.

According to Figure 10(a), although the loess has been compacted, there are still many overhead pores, some particles are still in point contact with each other, and the particles' outline is relatively clear [2, 42, 47]. However, when the content of fly ash reaches $10 \%$ (Figure 10(b)), compared with the mesostructure of compacted loess, although spherical fly ash particles are attached in the pores and particles of soil and there is a certain amount of hydrated cement produced due to hydration and flocculation of fly ash $[27,46]$, there are still a large number of overhead pores in the soil. Although the contact form between particles is partly transformed into surface contact $[2,42]$, there are still many unstable pointcontact forms. Therefore, the reinforcement effect of fly ash on the soil skeleton of fly ash modified loess with a content of $10 \%$ is still relatively weak, and the filling of overhead pores is relatively limited, so the dynamic parameters change a little. According to Figure 10(c), when the fly ash content reaches $15 \%$, more spherical fly ash particles and flocculent hydrate produced by fly ash 


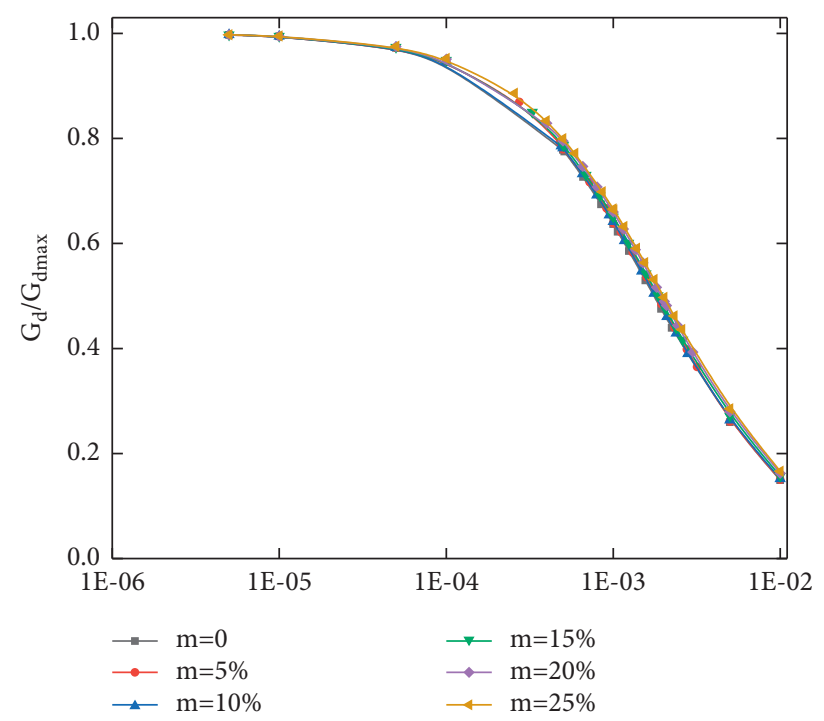

FIGURE 6: Dynamic shear modulus ratio dynamic shear strain curves of the fly ash treated loess.

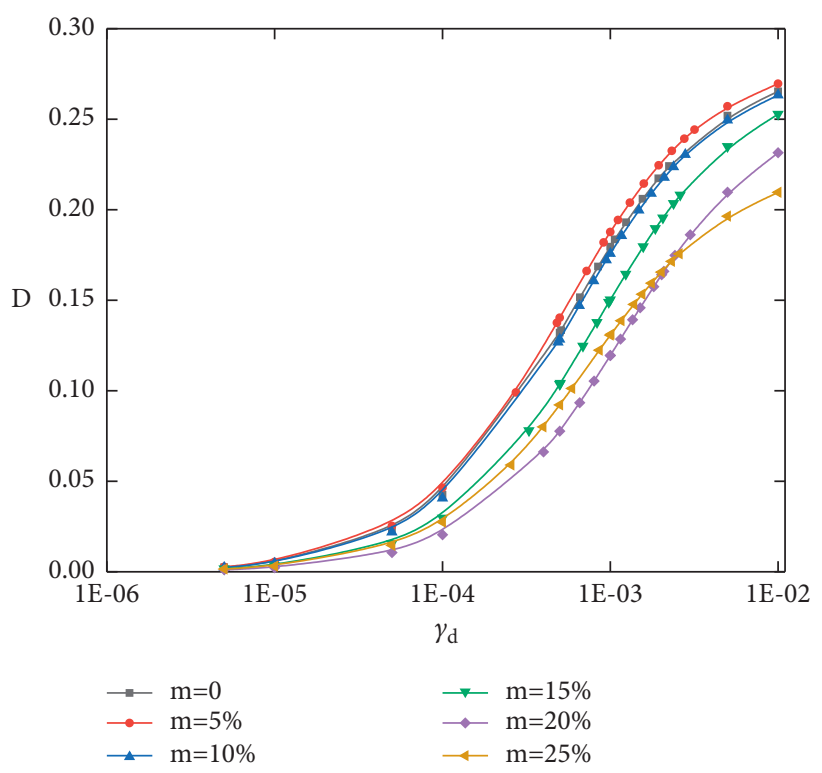

Figure 7: Damping ratio dynamic shear strain curves of the fly ash treated loess.

hydration, which can be seen in the field of vision, fill the large pores in the soil, and the outline of some soil particles tends to be fuzzy. Besides, the contact form between particles is mainly surface contact $[2,42]$. At this time, the dynamic stiffness and antideformation ability of soil at the macro level is further enhanced due to the enhanced cementation between particles produced by hydration reaction. According to Figure 10(d), when the fly ash content reaches 20\%, many spherical fly ash particles are distributed in the SEM image field. The particles of fly ash modified loess are well cemented by the flocculated products, which are generated after the hydration reaction of fly ash. The contact form between particles in the soil changes into surface contact or flocculent cementation contact, and the bonding strength between soil particles is significantly enhanced. At the same time, the spherical fly ash particles fill in the soil, which makes the overhead pores in the soil almost disappear, the medium and large pores are significantly reduced, and the integrity of the soil structure becomes stronger so that the dynamic stiffness and antideformation ability of soil is significantly enhanced. In addition, fly ash hydration reaction will consume part of the free water in the soil and reduce soil moisture content. According to the previous research results $[2,27,48]$, the moisture content has an obvious influence on the dynamic elastic modulus, damping ratio, and dynamic deformation of loess, and the dynamic stiffness and antideformation ability of soil will rapidly decrease with the increase in moisture content. Therefore, the free water 


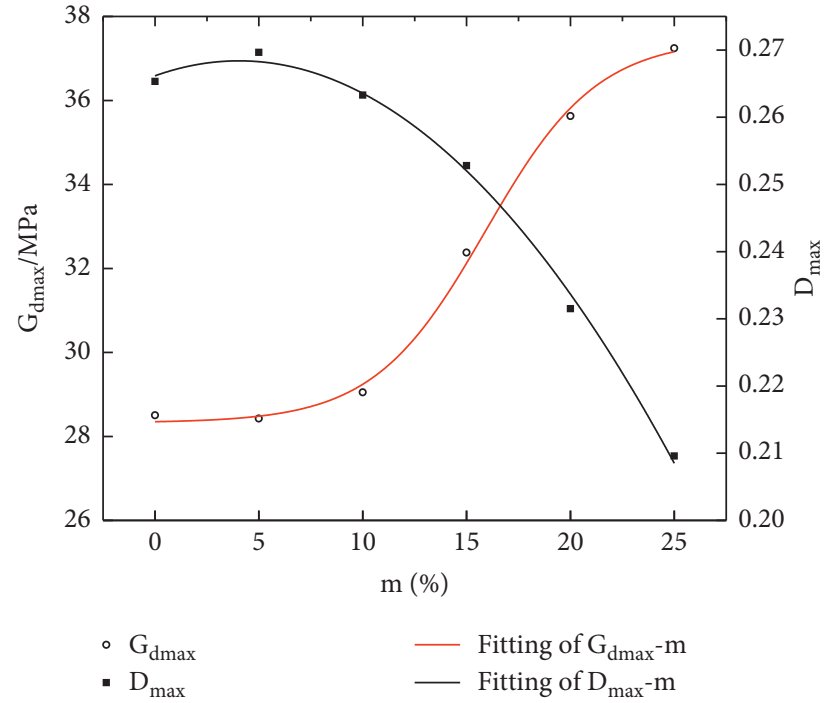

Figure 8: The maximum dynamic shear modulus and the maximum damping ratio of the fly ash treated loess.

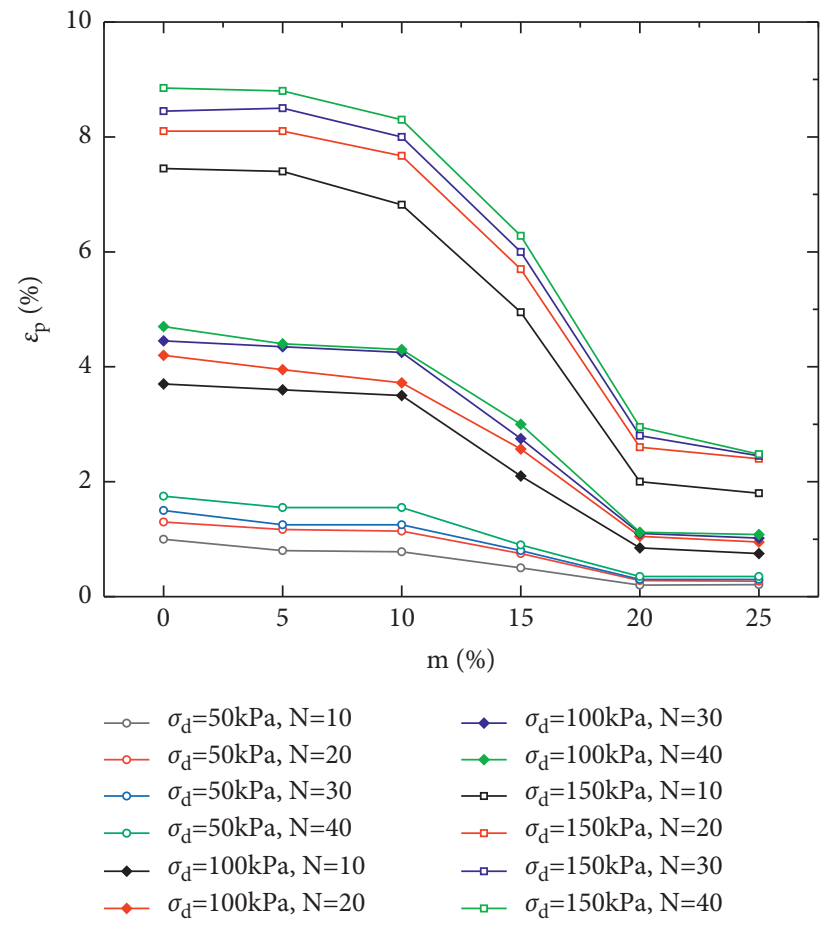

Figure 9: The dynamic residual strain curves of the fly ash treated loess with different fly ash contents. 


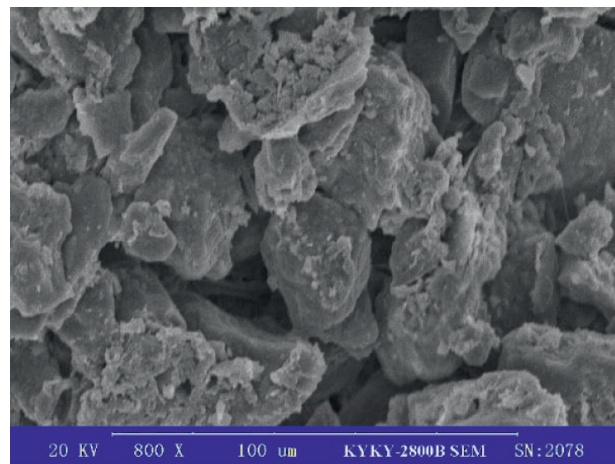

(a)

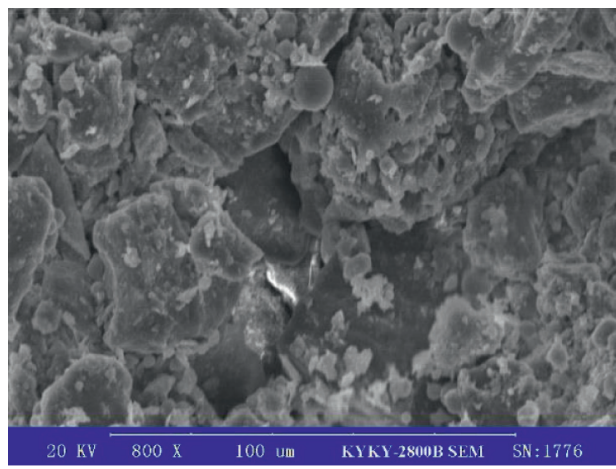

(c)

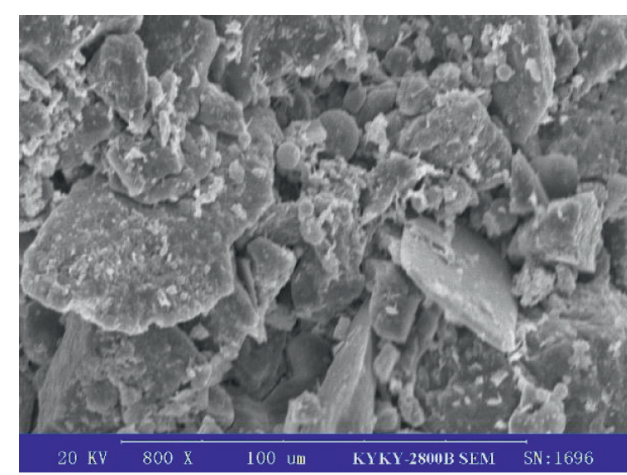

(b)

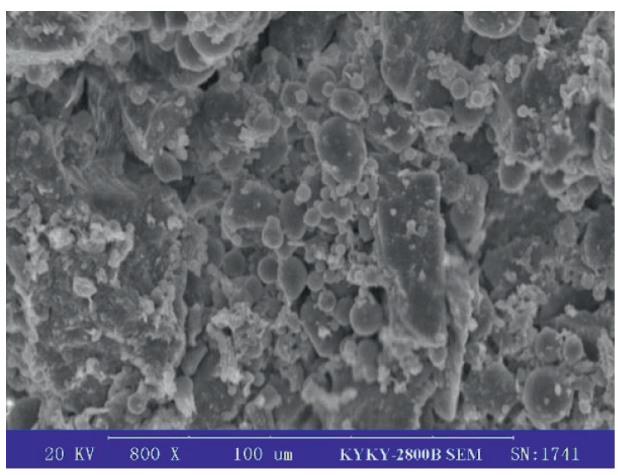

(d)

FIgure 10: SEM images of the fly ash modified loess: (a) $m=0$, (b) $m=10 \%$, (c) $m=15 \%$, and (d) $m=20 \%$.

of soil will be consumed by the hydration of fly ash in the fly ash modified loess, which will also be helpful to enhance the dynamic stiffness and antideformation ability of soil.

\section{Conclusion}

This work provided the dynamic stiffness and dynamic residual deformation behaviors of the fly ash modified loess. Based on the results, several conclusions can be drawn:

(1) The dynamic shear modulus ratio of fly ash modified loess with different fly ash content decreases gradually with the increase in dynamic shear strain. The shape of the curve is similar, but the attenuation rate difference is small. However, under the condition of the same dynamic shear strain, the damping ratio of fly ash modified loess shows an obvious difference with the different content of fly ash. When the fly ash content is large, the damping ratio of fly ash modified loess trends to decrease on the whole.

(2) With the increase in fly ash content, the maximum dynamic shear modulus of fly ash modified loess increases nonlinearly, and its growth trend presents the characteristics of slow growth, rapid growth, and slow growth. However, the maximum damping ratio first increases slowly and then decreases sharply with the increase in fly ash content.

(3) The dynamic residual strain of fly ash modified loess increases with the increase in dynamic stress and decreases with the increase in fly ash content. When the fly ash content is $10 \% \leq m \leq 20 \%$, the dynamic residual strain of fly ash modified loess decreases sharply. When the content of fly ash exceeds $20 \%$, the decreasing trend of dynamic residual strain becomes slow.

(4) When the fly ash content is $20 \%$, the dynamic stiffness of fly ash modified loess is obvious, and the antiresidual deformation ability of soil is effectively improved. Considering the seismic performance and treatment cost of the foundation, fly ash content of $20 \%$ can be used as the recommended value for the seismic treatment of fly ash modified loess foundation.

\section{Data Availability}

All data included in this study are available upon request by contacting the corresponding author. 


\section{Conflicts of Interest}

The authors declare no conflicts of interest to report regarding the present study.

\section{Acknowledgments}

This work was funded under the Funding of Science for Earthquake Resilience (Grant Nos. XH20057, XH21034, and XH21035Y), the Special Fund for Innovation Team, Gansu Earthquake Agency (Grant Nos. 2020TD-01-01), and the grant of the National Natural Science Foundation of China (No. 51778590). The authors are grateful to Dr. Mohamed Elmujtaba and Dr. Guo Peng for their helpful comments in language during the revision process of this work.

\section{References}

[1] T. S. Liu, Loess and the Environment, Science Press, Beijing, China, 1985.

[2] G. R. Gao, "Loess microstructure classification and loess collapsible," Science China, vol. 12, no. 1, pp. 203-204, 1980.

[3] H. Ma, Y. Wu, J. g. Feng, R. Xu, S. Wu, and Q. Wang, "Research on recent GPS crustal deformation characteristics in the northeastern edge of qinghai-tibet plateau," Journal of Physics: Conference Series, vol. 910, no. 1, Article ID 012028, 2017.

[4] Z.-K. Shen, J. Sun, P. Zhang et al., "Slip maxima at fault junctions and rupturing of barriers during the 2008 Wenchuan earthquake," Nature Geoscience, vol. 2, no. 10, pp. 718-724, 2009.

[5] I. F. Jefferson, D. Evstatiev, D. Karastanev, N. G. Mavlyanova, and I. J. Smalley, "Engineering geology of loess and loess-like deposits: a commentary on the Russian literature," Engineering Geology, vol. 68, no. 3-4, pp. 333-351, 2003.

[6] Y. Li, "A review of shear and tensile strengths of the Malan Loess in China," Engineering Geology, vol. 236, pp. 4-10, 2018.

[7] E. Derbyshire, X. M. Meng, and T. A. Dijkstra, Landslides in the Thick Loess Terrain of North-West China, John Wiley \& Sons, Hoboken, NJ, USA, 2000.

[8] R. Q. Huang, "Some catastrophic landslides since the twentieth century in the southwest of China," Landslides, vol. 6, pp. 69-81, 2009.

[9] F. Zhang and G. Wang, "Effect of irrigation-induced densification on the post-failure behavior of loess flowslides occurring on the Heifangtai area, Gansu, China," Engineering Geology, vol. 236, pp. 111-118, 2018.

[10] L. Wang, Z. Wu, and K. Xia, "Effects of site conditions on earthquake ground motion and their applications in seismic design in loess region," Journal of Mountain Science, vol. 14, no. 6, pp. 1185-1193, 2017.

[11] Q. Wang, Z. M. Wang, Y. Q. Su et al., "Characteristics and mechanism of the landslide in yongguang village, minxian county, China," Natural Hazards, 2020, https://doi.org/10. 1007/s11069-020-04360-7.

[12] Z. Q. Wang, Y. S. Luo, R. R. Wang, L. G. Yang, and D. Y. Tan, "Experimental study on dynamic shear modulus and damping ratio of undisturbed loess in different regions," Chinese Journal of Geotechnical Engineering, vol. 32, no. 9, pp. 1464-1469, 2010.

[13] L. S. Deng and W. Fan, "Study of dynamic stress-strain relationship of loess under seismic loading," Chinese Journal of Rock Mechanics and Engineering, vol. 31, no. S1, pp. 31743180, 2012.
[14] T. F. Gu, J. D. Wang, and J. Wang, "Laboratory and numerical studies on seismic subsidence of loess subgrade a long Zhengzhou - xi'an High-Speed railway," Journal of Engineering Geology, vol. 17, no. 4, pp. 557-562, 2009.

[15] J. Wang, Q. Wang, L. M. Wang, P. Wang, and S. Chai, "Laboratory analysis of seismic subsidence of loess subgrade of high-speed railway under random seismic loading," Chinese Journal of Rock Mechanics and Engineering, vol. 33, no. S2, pp. 4239-4245, 2014.

[16] Z. Liu, C. S. Cai, F. Liu, and F. Fan, "Feasibility study of loess stabilization with fly ash-based geopolymer," Journal of Materials in Civil Engineering, vol. 28, no. 5, Article ID 04016003, 2016.

[17] M. Li, C. Fang, S. Kawasaki, and V. Achal, "Fly ash incorporated with biocement to improve strength of expansive soil," Scientific Reports, vol. 8, no. 1, 2018.

[18] S. Bin-Shafique, K. Rahman, and I. Azfar, "The Effect of Freezing-Thawing Cycles on Performance of Fly Ash Stabilized Expansive Soil Subbases," in Proceedings of the GeoFrontiers Congress 2011, pp. 697-706, ASCE, Dallas, TX, USA, March 2011.

[19] B. Kim, M. Prezzi, and R. Salgado, "Geotechnical properties of fly and bottom ash mixtures for use in highway embankments," Journal of Geotechnical and Geoenvironmental Engineering, vol. 131, no. 7, pp. 914-924, 2005.

[20] M. Sumesh, A. Kalita, and B. Singh, "An experimental investigation on strength properties of fly ash blended soils treated with cement," Journal of Environmental Research \& Development, vol. 5, no. 2, pp. 322-329, 2010.

[21] S. Q. Chen, "Analysis of application of fly ash as filling material for railway embankment," Journal of Railway Engineering Society, vol. 20, no. 2, pp. 42-47, 2003.

[22] A. Lav, M. Lav, and A. Goktepe, "Analysis and design of a stabilized fly ash as pavement base material," Fuel, vol. 85, no. 16, pp. 2359-2370, 2006.

[23] A. H. Aydilek and S. Arora, "Fly ash amended soils as highway base materials," Journal of Materials in Civil Engineering, vol. 17, no. 6, pp. 1032-1041, 2005.

[24] R. Wu, X. Chen, and W. Qian, "Experimental research on stabilization of red clay with cement and fly ash," Industrial Construction, vol. 36, no. 7, pp. 29-30, 2006.

[25] T. T. Guo, B. P. Zhang, Z. G. Tian, and D. H. Lv, "Study on engineering characteristic of lime-fly ash loess," Chinese Journal of Geotechnical Engineering, vol. 26, no. 5, pp. 719-721, 2004.

[26] S. Wang, Q. Lv, H. Baaj, X. Li, and Y. Zhao, "Volume change behaviour and microstructure of stabilized loess under cyclic freeze-thaw conditions," Canadian Journal of Civil Engineering, vol. 43, no. 10, pp. 865-874, 2016.

[27] Q. Wang, L. M. Wang, X. M. Zhong et al., "Dynamic behavior and constitutive relationship of saturated fly ash-modified loess," European Journal of Environmental and Civil Engineering, vol. 25, no. 7, 2019.

[28] Z. N. Gao, Z. H. Zhou, J. Wang, H. X. Zheng, X. M. Zhong, and C. C. Zhao, "Anti-liquefaction properties of saturated loess improved by fly ash," China Earthquake Engineering Journal, vol. 40, no. 1, pp. 105-110, 2018.

[29] J. Wang, Z. N. Gao, G. F. Che et al., "Seismic subsidence behavior of fly-ash-modified loess under dynamic loading," China Earthquake Engineering Journal, vol. 38, no. 5, pp. 751-756, 2016.

[30] J. Wang, Q. Wang, P. Wang, X. M. Zhong, and C. F. Chai, "Effect of adding amount of fly ash on dynamic constitutive relationship of modified loess," Chinese Journal of Geotechnical Engineering, vol. 35, no. s1, pp. 156-160, 2013. 
[31] J. Wang, Q. Wang, X. M. Zhong, P. Wang, and S. F. Chai, "Experimental study of loess seismic subsidence under the coupling effect of fly ash and dynamic loading," Hydrogeology \& Engineering Geology, vol. 41, no. 6, pp. 70-75, 2014.

[32] L. M. Wang, Q. Wang, X. M. Zhong, P. Guo, H. M. Liu, and J. Wang, "Study on improvement methods of saturated loess ground," in Proceedings of the 7th China-Japan Geotechnical Symposium, pp. 342-346, Sanya, China, March 2018.

[33] ASTM, Standard Test Methods for Laboratory Determination of Density (Unit Weight) of Soil Specimens, ASTM D72632009, West Conshohocken, PA, USA, 2009.

[34] ASTM, Standard Test Method for Determination of Water (Moisture) Content of Soil by the Microwave Oven Method, ASTM D4643-2000, West Conshohocken, PA, USA, 2000.

[35] ASTM, Standard Test Methods for Liquid Limit, Plastic Limit, and Plasticity index of Soils, ASTM D4318-2010, West Conshohocken, PA, USA, 2010.

[36] ASTM, Standard Test Methods for Specific Gravity of Soil Solids by Water Pycnometer, ASTM D854-2000, West Conshohocken, PA, USA, 2000.

[37] ASTM, Standard Test Method forParticle-Size Analysis of Soils1, ASTM D422-2007, West Conshohocken, PA, USA, 2007.

[38] ASTM, Standard Test Methods for the Determination of the Modulus and Damping Properties of Soils Using the Cyclic Triaxial Apparatus, ASTM D3999-2011, West Conshohocken, PA, USA, 2011.

[39] ASTM, Standard Test Method for Load Controlled Cyclic Triaxial Strength of Soil, ASTM D5311-2011, West Conshohocken, PA, USA, 2011.

[40] H. B. Seed and I. M. Idriss, "Simplified procedure for evaluating soil liquefaction potential," Journal of the Soil Mechanics and Foundations Division, vol. 97, no. 9, pp. 1249-1273, 1971.

[41] G. Y. Cheng, Study on Correlation between Shear-Wave Velocity and Liquefaction Resistance of Saturated Sand, $\mathrm{PhD}$ thesis, Tianjin University, Tianjin, China, 2003.

[42] W. Liu, Q. Wang, G. Lin, and W. Chen, "Effect of pre-dynamic loading on dynamic liquefaction of undisturbed loess," Bulletin of Earthquake Engineering, vol. 18, no. 13, pp. 5779-5806, 2020.

[43] X. M. Zhong, Q. Wang, Z. Z. Liu et al., "Dynamic strength of fly ash-modified loess subgrade under influences of dryingwetting cycle," Chinese Journal of Geotechnical Engineering, vol. 42, no. s1, pp. 95-99, 2020.

[44] L. Guo, J. D. Wang, and T. F. Gu, "A study of loess seismic subsidence of tableland to the north Weihe River in Baoji City," Hydrogeology \& Engineering Geology, vol. 39, no. 2, pp. 61-65, 2012.

[45] B. O. Hardin and V. P. Drnevich, "Shear modulus and damping in soils: design equations and curves," Journal of the Soil Mechanics and Foundations Division, vol. 98, no. 7, pp. 667-692, 1972.

[46] Q. Xia, Y. H. Yang, and X. Geng, "Experimental study on ashlime or fly ash-cement loess filling," Journal of Lanzhou Jiaotong University, vol. 27, no. 3, pp. 40-43, 2008.

[47] G. Y. Li, W. Ma, Y. H. Mu, F. Wang, S. Z. Fan, and Y. H. Wu, "Effects of freeze-thaw cycle on engineering properties of loess used as road fills in seasonally frozen ground regions, North China," Journal of Mountain Science, vol. 14, no. 2, pp. 356-368, 2017.

[48] L. M. Wang, Y. C. Shi, and X. Liu, Loess Dynamics, pp. 40-143, Seismological Press, Beijing, China, 2003. 